\title{
Comparison of Callus Initiation and Regeneration Frequency for Two Submerge Tolerant Rice (Oryza sativa)
}

\author{
R. Bhuiyan ${ }^{1}$, Md. Abunasar Miah ${ }^{1}$, Shahriar Kabir Shakil ${ }^{1}$, Mohammad Ferdous \\ Ikbal $^{2}$, A.T.M.J. Mosnaz ${ }^{1}$, Md. Hammadul Hoque ${ }^{1}$, Gokul Chandra Biswas ${ }^{1}$ and \\ Shamsul H. Prodhan ${ }^{1 *}$ \\ ${ }^{1}$ Department of Genetic Engineering and Biotechnology, School of Life Sciences, Shahjalal University of \\ Science and Technology Sylhet-3114, Bangladesh. \\ ${ }^{2}$ Scientific officer, Biotechnology Division, Bangladesh Institute of Nuclear Agriculture, Mymensingh, \\ Bangladesh.
}

\begin{abstract}
This study was undertaken to find out the in vitro callus induction and organogenesis potential of submerged tolerant rice varieties. MS media supplemented with different concentrations of 2, 4- D $(0.5,1.0,1.5,2.0,3.0$, and $4.0 \mathrm{mg} \mathrm{L}-1)$ were used for callus induction from the mature dehusked rice seeds. Callus derived from the $3.0 \mathrm{mg} / \mathrm{l} 2,4-D$ showed the best results for callus induction (BRRI dhan 52 showed $45.5 \%$ and FR13A showed 90\%). For regeneration of plantlets MS media with different concentrations of NAA, BA, and Kinetin were employed. The highest regeneration frequencies were $35 \%$ for BRRI 52 and $83 \%$ for FR13A, the highest average shoots were recorded at the MS media supplemented with $2 \mathrm{mg} / \mathrm{L}$ kinetin $+2 \mathrm{mg} / \mathrm{L} B A+1 \mathrm{mg} / \mathrm{L} \mathrm{NAA}$. The maximum shoot produced after 3.5 weeks and multiple shoots were apparent in the first subculture. In regeneration media root formation frequency was not considerable, so again shoots were given to the root formation media with three media composition. Best result found from hormone free MS Basal media (94\% for FR13A and 87\% for BRRI dhan 52). After hardening the plantlets were transferred to field.
\end{abstract}

Keyword: BRRI dhan 52, FR13A, In Vitro; Organogenesis, Regeneration, and Submerged Tolerant.

\section{Introduction}

Rice (Oryza sativa L) is the most important food crop of the developing world. It provides up to two thirds of calories for more than two billion people in Asia [2]. The genus Oryza includes 21 wild species and 2 cultivated species, Oryza glaberrima and $O$. sativa. Whereas $O$. glaberrima is cultivated in restricted areas of western Africa, $O$. sativa is cultivated globally. Since the time of its initial domestication, Asian cultivated rice has been moved across the globe with migrating human populations [7]; rice cultivation can now be found on all continents except Antarctica and feeds more than half of the world's population [11]. Each year an estimated 408,661 million metric tons of rice is consumed, supplying $20 \%$ of the world's total caloric intake [3]. The floodplains of Bangladesh are one of the regions where the rice plant was first domesticated around 5th millennium B.C. Bangladesh is also the place where rice production systems of various eco-seasonal characteristics evolved over centuries of rice farming experience and have been sustained. Fertile lands and hard-working farmers are the biggest assets of the rice production sector in Bangladesh (Bangladesh Rice Foundation). Plant tissue culture techniques have provided a potential and fundamental as well as applied research for the improvement of many crops. Rice is the staple food of around $30-40 \%$ of the world population. It is an important source of carbohydrate for human consumption and also provides feed and forage. Global population is expected to reach around 10 billion by 2050 . Thus there is a need to improve upon the yield of the local varieties/cultivars, because loss in production could lead to hunger and famine, especially in the developing countries [1]. For this an efficient protocol for plant regeneration needs to be developed to achieve transgenic rice. So this experiment was conducted to studies on growth media effect on callus initiation and regeneration of two indica rice varieties, one is BRRI dhan 52 (The NSB approved BR11Sub1-R1 (IR85260-66-654-Gaz 2) as BRRI dhan52 for flash flood prone areas in T. Aman season. This submergence tolerant rice variety can produce 4.5-5.0 ton/ha grain yield despite a 10-14 days of flash flooding) and other variety, FR13A (submerge tolerant local variety of Eastern India) to Integrate tissue culture and in vitro techniques into varietal improvement with special emphasis on rice, to Develop an efficient protocol for regeneration of theses varieties and then study their tolerance against abiotic stress, such as submerge tolerance and to Obtain calli, followed by regeneration of the regenerated plants for submerge tolerance in rice was investigated. 


\section{Materials And Methods}

This research work was conducted at the Department of Genetic Engineering and biotechnology, Shahjalal University of Science \& Technology (SUST), Sylhet. Mature seeds of two indica rice (Oryza sativa) varieties BRRI dhan 52 and FR13A (Indian variety), were used for callus production and shoot regeneration experiments. Mature seeds were de-husked, surface sterilized with $70 \%$ ethyl alcohol for 30 sec, and then for 12-15 min with 5\% sodium hypochlorite (commercial bleach is mainly hypochlorite). Surface sterilized seeds were rinsed several times with sterile distilled water before inoculation on callus induction medium, consisting of MS basal organic and inorganic components [9] supplemented with $3.0 \%$ sucrose and $2,4 \mathrm{D}$ at $(0.5$ to 4$) \mathrm{mg} / \mathrm{L}$ Media was prepared following the protocol of Prodhan et al. [10]. Media was autoclaved at 15 pound square inch (psi) for twenty minutes at $121^{\circ} \mathrm{c}$. The $\mathrm{pH}$ of the media was adjusted at 5.8-6.0 by adding $1 \mathrm{M} \mathrm{NaOH}$. For plant regeneration, the embryogenic part of calli was cut into small pieces after removing non embryogenic part. Calli were then inoculated on regeneration media i.e. MS salts and vitamins with five different combination and concentrations of hormones. There was also prepared root regeneration medium to regenerate roots with MS medium +3 different combination of hormones (hormone free: $1 \mathrm{mg} / \mathrm{L}$ kinetin $+.5 \mathrm{mg} / \mathrm{L} \mathrm{NAA} ; 1.5 \mathrm{mg} / \mathrm{L}$ kinetin + $0.5 \mathrm{mg} / \mathrm{L} \mathrm{NAA}$ ). After experiment data collected were subjected to analysis:

Table 2.1: Plant regeneration media

\begin{tabular}{llllll}
\hline MEDIA & MEDIA TYPE & \multicolumn{4}{l}{ GROWTH REGULATORS CONCENTRATIONS } \\
\cline { 3 - 6 } & & Kinetin & BA & NAA & IBA \\
$\mathbf{R}_{\mathbf{1}}$ & M.S & $2 \mathrm{mg} / \mathrm{L}$ & $2 \mathrm{mg} / \mathrm{L}$ & $1 \mathrm{mg} / \mathrm{L}$ & \\
$\mathbf{R}_{\mathbf{2}}$ & M.S & $1 \mathrm{mg} / \mathrm{L}$ & $4 \mathrm{mg} / \mathrm{L}$ & $2 \mathrm{mg} / \mathrm{L}$ & $0.5 \mathrm{mg} / \mathrm{L}$ \\
$\mathbf{R}_{\mathbf{3}}$ & M.S & & $2 \mathrm{mg} / \mathrm{L}$ & & $0.5 \mathrm{mg} / \mathrm{L}$ \\
$\mathbf{R}_{\mathbf{4}}$ & M.S & & $4 \mathrm{mg} / \mathrm{L}$ & $1.5 \mathrm{mg} / \mathrm{L}$ \\
\hline
\end{tabular}

*** Here $\mathrm{R}=$ Regeneration media

\section{Results And Discussion}

After 2-3 days of culturing, shoots began to form and after 3-4 days, callus began to form from the base point of shoots and the scutellum of the cultured seed in all the media. Both embryogenic and non-embryogenic calli were initiated. Embryogenic calli were found to be yellow to white, dry, compact and nodular. On the other hand, non-embryogenic calli appeared to be watery, light yellow to tan and non-nodular. After 3 weeks, the first subculture was carried out and calli were removed from seed and shoot and transferred onto fresh media. Without hormone $0 \%$ callus formation was observed after 3-4 weeks. MS medium supplemented with various concentrations of 2, 4-D developed shoots after 2-3 days of culture but later the shoots ceased to grow further. Mostly 2, 4-D has been used as the only growth regulator in callus induction media [6, 17]. Callus induction in rice was found highly variable and genotype specific. Between two studied varieties, the variety FR13A produced $90 \%$ callus from the inoculated seeds, which was significantly higher than other variety (Fig 3.1). Frequency of callus induction from the seeds of variety BRRI dhan 52 was $45.5 \%$ (Fig 3.1). This finding is accordance with the reports of several researchers [5, 13 and 12].

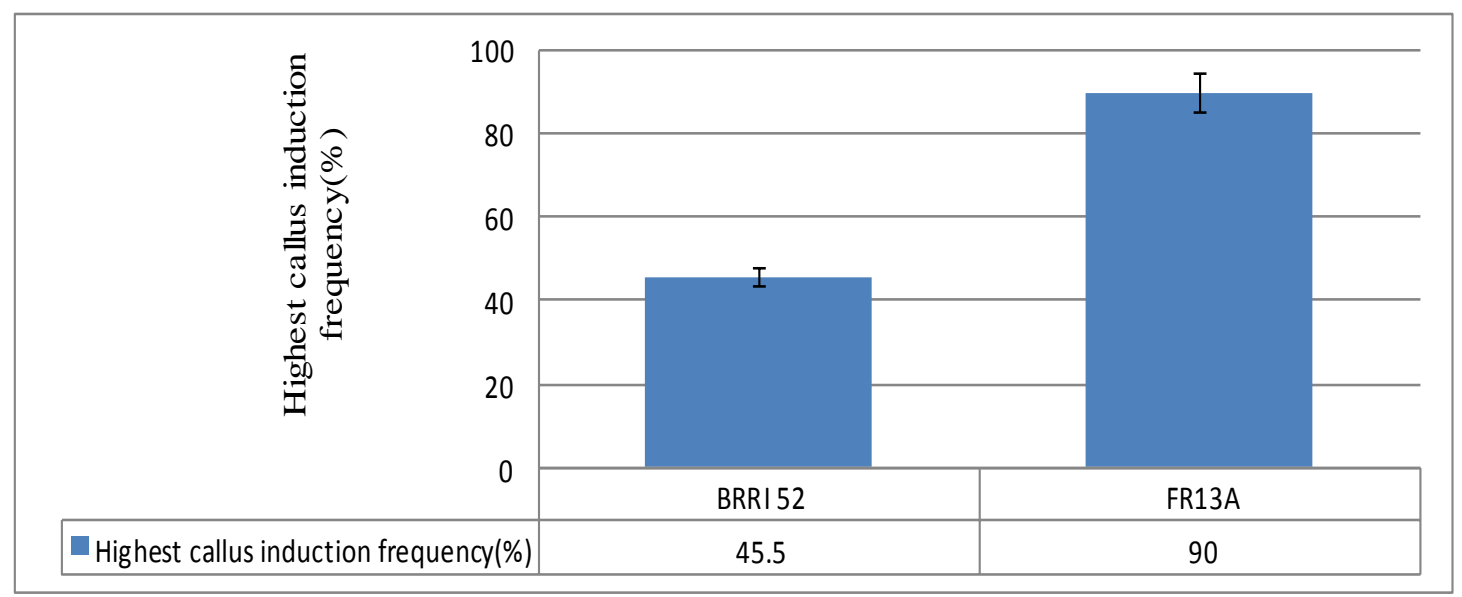

Figure 3.1 Effect of varieties on callus induction 
Evans et. al. [4] Noticed that 2, 4-D is effective in callus induction of cereal. Yamada et. al. [16] Reported that Callus induction depends on the 2, 4-dichlorophenoxyacetic acid (2, 4-D) concentration only. Addition of adequate levels of 2, 4-D into a basal medium resulted in prolific callus formation from a variety of rice explants [8]. Here the study showed that the presence of 2, 4-D in the culture medium was critical for callus induction of both varieties BRRI 52 and FR13A (Fig 3.2). Highest callus induction rate is $75 \%$ at the concentration of $3 \mathrm{mg} / \mathrm{L}$ hormone (2, 4-D).

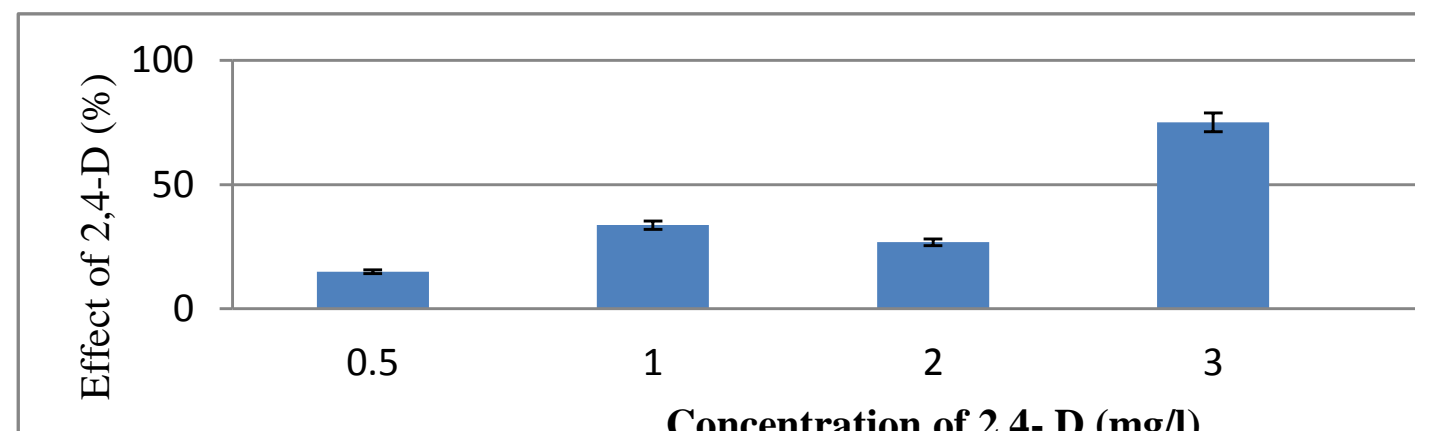

Figure 3.2 Effect of different concentration of 2, 4- D (mg/L) on callus induction.

Calli obtained in the previous culture media (MS + 2, 4-D) were inoculated for next step of the experiment. Suitable calli were selected for inoculation in the MS medium supplemented with various combinations of growth hormones. These calli were compact in texture and of a yellowish and dark green color. This greening was due to the production of green projections, which probably were embryoids. These embryoids like structures developed into plantlets after 2.5 weeks of culture on a fresh medium (Fig. 3.4). The shoot formation frequencies of BRRI 52 and FR13A are given table 3.1.

Table 3.1 Shoot regeneration frequency (\%) of BRRI 52 \& FR13A

\begin{tabular}{lcc}
\hline Media names & $\begin{array}{l}\text { Shoot regeneration frequencies (\%) } \\
\text { of FR13A }\end{array}$ & \multicolumn{2}{c}{$\begin{array}{l}\text { Shoot regeneration frequencies (\%) of } \\
\text { BRRi dhan 52 }\end{array}$} \\
\hline $\mathbf{R}_{\mathbf{1}}$ & 83.4 & 35 \\
\hline $\mathbf{R}_{\mathbf{2}}$ & 80 & 16.7 \\
$\mathbf{R}_{\mathbf{3}}$ & 33.33 & 0 \\
\hline $\mathbf{R}_{\mathbf{4}}$ & 45 & 8 \\
\hline $\mathbf{R}_{\mathbf{5}}$ & 40 & 8 \\
\hline
\end{tabular}

*** $\mathbf{R}=$ Regeneration media

These hormones induced formation of shoot buds, which later on developed into complete plantlets. In present experiment results are in agreement with those of Wang YQ et. el. [15] who reported that high concentration of cytokine and low of auxin promoted plantlet regeneration. Small green projections appeared on the callus, which later developed into shoot buds. These buds developed into plantlets, when the callus, along with the shoot buds, was subculture on the same media. Few cultures showed root but maximum did not. So, Rooting frequency was also enhanced by further addition of different combination of growth hormones and without hormone with MS basal medium (table 3.2).

Table 3.2 Root regeneration frequency

\begin{tabular}{lcc}
\hline Media names & \multicolumn{2}{c}{ Root regeneration frequency (\%) } \\
\cline { 2 - 3 } & BRRI 52 & FR13A \\
$\mathbf{H F}$ & 87 & 94 \\
$\mathbf{K N}_{\mathbf{1}}$ & 16 & 37 \\
$\mathbf{K N}_{\mathbf{2}}$ & 48.9 & 78.24 \\
\hline
\end{tabular}

$* * * \mathrm{HF}=$ Hormone Free; $\mathrm{KN}=$ Kinetin + NAA

Here hormone free (HF) medium showed very good result after 5 days. After shoot and root regeneration of both varieties, these were transferred to soil for their adaptation in the natural environment. A soil-made pot full of soil with adequate amount of water was prepared for rice plant transformation. After 10 days of the transformation, the result was positive. Tian Wenzhong et. el. [14] Observed in order to improve the frequency of plant regeneration from callus in indica rice, the influences of different factors on plant regeneration were investigated. Supplement with cytokinins (KT, BAP, Zeatin or 2ip, $1 \mathrm{mg} / \mathrm{l})$ and NAA(1 mg / l), or supplement 
with thidiazuron (OS mg / l) in the induction medium or subculture medium; and partial desiccation of callus before transfer to regeneration medium have been found significantly increase the frequency of plant regeneration in indica rice. 5 - 14 folds more plants were obtained than untreated control by the combination of these treatments with indica varieties TN1, IR72 and IR, also support the present study where regeneration(shoot and root) found by the similar way.

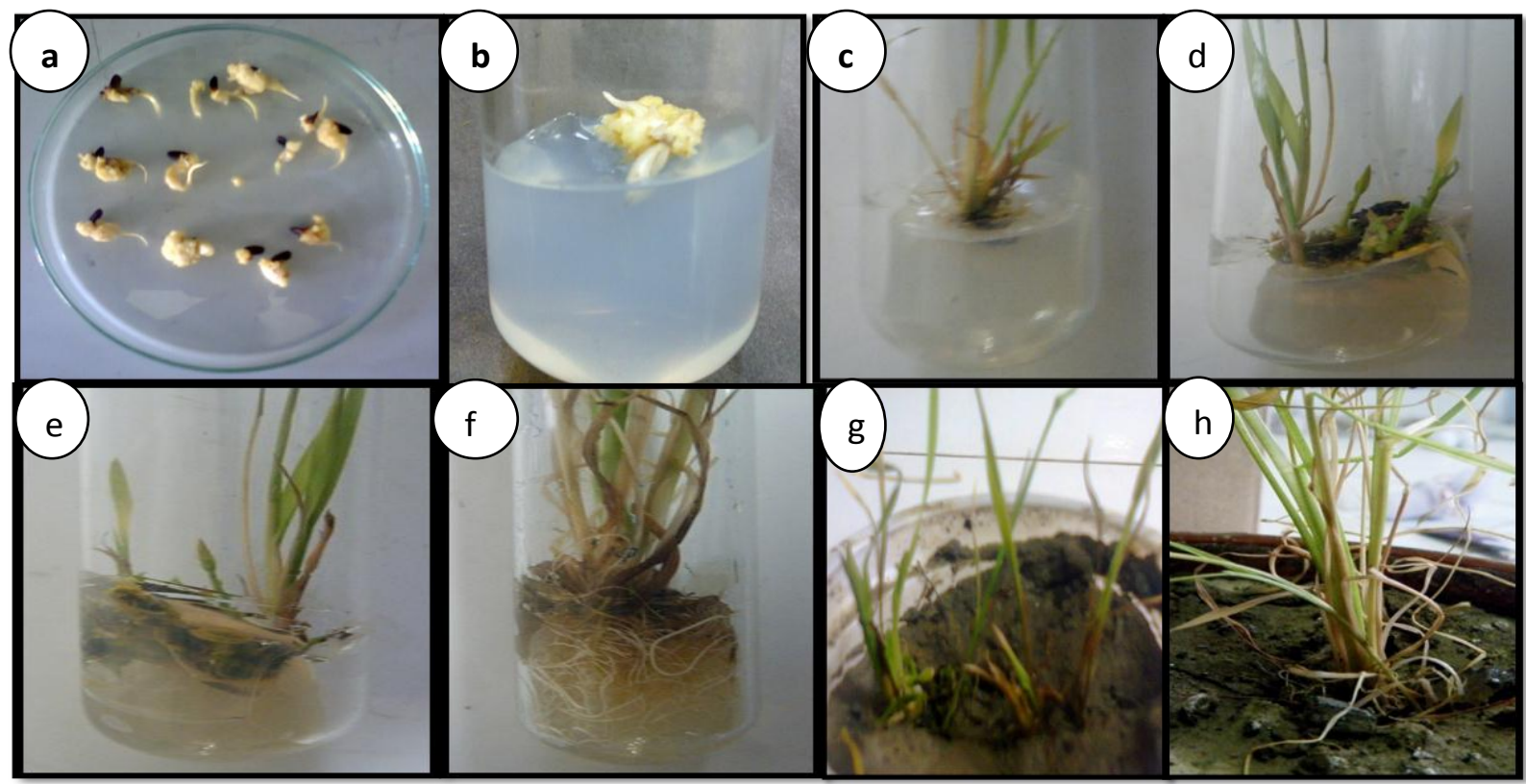

Figure 3.3 Callus formation of (a) FR13A and (b) BRRI dhan 52, regeneration of shoots after first subculture (c) BRRI 52 and (d) FR13A, root formation (e) BRRI 52 and (f) FR13A, acclimatization of (g) BRRI 52 and (h) FR13A

\section{Conclusion}

The investigation was conducted to study on growth medium effect of callus initiation and regeneration system for two rice varieties using mature seed as explants. Frequency of callus induction from the seeds of variety BRRI dhan 52 was $45.5 \%$ and FR13A was $90 \%$. Plant growth regulators play a central role in plant tissue culture. In most cases, 2,4-D as a strong synthetic auxin was sufficient to initiate and sustain embryogenic callus growth in rice and has been used as the only growth regulator in callus induction media. In this study more callus was found from the $3 \mathrm{mg} / \mathrm{L}$ 2,4-D. In shoot regeneration media Kinetin( $2 \mathrm{mg} / \mathrm{L})+\mathrm{BA}(2$ $\mathrm{mg} / \mathrm{L})+\mathrm{NAA}(1 \mathrm{mg} / \mathrm{L})$ composition with MS medium gave the best result for both rice varieties. But yet root was not appeared here, so again prepared root regeneration medium and hormone free MS medium gave the highest result.

\section{Acknowledgement}

We are grateful to the Plant Genetic Engineering Laboratory of the Department of Genetic Engineering and Biotechnology, Shahjalal University of Scinece and Technology, Sylhet-3114, Bangladesh.

\section{References}

[1]. Bano S., Jabeen M., Rahim,F., and Ilahi, I. 2005. Callus induction and regeneration in

[2]. seed explants of rice (Oryza Sativa Cv. Swat-Ii). Pak. J. Bot., 37(3): 829-836, 2005

[3]. Beena, C. (2006) Genetic effect on the regeneration of the calli of rice, Indian J. Crop Science, 1(1-2): 207-208

[4]. Clay J. W. (2004) World Agriculture and the Environment: A Commodity-By-Commodity Guide to Impacts and Practices (Island, Washington, DC), pp 38,8390.

[5]. Evans, D.A., W.R. Sharp and C.E. Flick. 1981. Plant regeneration from cell cultures. Hort. Rev.3: $214-314$.

[6]. Jubair, T.A., U. Salma, N. Haque, F. Akter, I.J. Mukti, A.K.M.F. Haque and M.R. Ali, 2008. Callus induction and regeneration of local rice (Oryza sativa L.) variety topa. Asian J. Plant Sci., 7: 514-517.

[7]. Katiyar SK, Chandel G, Singh P, Pratibha R (1999). Genetic variation and effect of 2,4-D in in-vitro plant regeneration in indica rice cultivars. Oryza. 36:254-256.

[8]. Khush G. (1997). Origin, dispersal, cultivation and variation of rice. Plant Mol. Biol. 35:25-34.

[9]. Morita M, Xing X H, Unno H. Synchronized shoot regeneration of rice (Oryza sativa L.) calli on solid medium by adjustment of intracellular 2,4-D concentration. Plant Cell Rep, 1999, 18: 633-639.

[10]. Murashige, T. and Skoog, F. (1962). A revised medium for rapid growth and bioassay with tobacco tissue culture. Physiol. Plant. $15: 472-493$ 
[11]. Prodhan, S.H., K. Nagamiya, A. Komamine and Y. Hirai 2001. Regeneration response of indica and japonica rice in different media. Bangladesh Journal of Breeding and Genetics, 14(2): 01-06.

[12]. Sasaki T. (2001). Rice genome analysis to understand the rice plant as an assembly of genetic codes . Photosynth. Res. 70:119-127.

[13]. Summart, J., Panichajakul,S., Prathepha, P. and Thanonkeo P. 2008. Callus Induction and Influence of Culture Condition and Culture Medium on Growth of Thai Aromatic Rice, Khao Dawk Mali 105, Cell Culture. World Applied Sciences Journal 5 (2): $246-$ 251.

[14]. Tariq, M., Ali, G., Hadi, F., Ahmad, S., Ali, N. and Shah A. A. 2008. Callus induction and in vitro plant regeneration of rice (Oryza sativa $\mathrm{L}$,) under various conditions. Pakistan journal of Biological Sciences 11 (2): 255- 259.

[15]. Tian Wenzhong, Iam Rance, Elunialai Sivamani, Claud auquet and Roger N. Beachy,1994. Frequency in vitro indica rice.Chinese Journal of GeneticsVolume 21.

[16]. Wang YQ, Duan ZG, Huang JK, Liang CY 2004. Efficient regeneration from in vitro culture of young panicles of rice (Oryza sativa L.). Chinese Bull Bot 21:52-60.

[17]. Yamada Y., Kenji T., and Eiichi T. 1967. Callus Induction in Rice, Oryza sativa L. Proc. Japan Acad., 43 156-160.

[18]. Zhenyu G, Gaozy HD, Huang DN (1999). Some factors influencing callus formation and plant regeneration in indica rice varieties. Plant. Physiol. Comm. 35:113-115. 